\title{
Factors affecting the exposure, vulnerability and emergency medical service capacity for victims of road traffic incidents in Kampala Metropolitan Area: a Delphi study
}

\author{
Joseph Kimuli Balikuddembe ${ }^{1,2}$ (D) Ali Ardalan ${ }^{1,3,4^{*}}$, Davoud Khorasani-Zavareh ${ }^{5,6,7}$, Amir Nejati $^{1,8}$ and Stephen Kasiima9
}

\begin{abstract}
Background: The Kampala Metropolitan Area (KMA) is the fastest developing region in Uganda. Over recent years, this has placed exponential demand on the road sector, which consequently has contributed to rapid growth in motorized vehicles which, predisposes the region to a high risk of road traffic incidents (RTIs). A number of concerted road safety and post-crash management measures to respond to RTIs in the KMA in particular and Uganda as a whole have been undertaken. However, there is a need to greatly improve the measures by better identifying the factors influencing the exposure, vulnerability and emergency medical service (EMS) capacity for RTI victims. The present study seeks to investigate and reveal these factors.
\end{abstract}

Methods: A Delphi technique employing a questionnaire and involving a multidisciplinary panel of experts was used in three rounds.

Results: The ten (10) most important factors affecting the exposure, vulnerability and EMS capacity for victims of RTIs in the KMA were identified. Socio-cultural, infrastructure and road safety aspects were the factors most identified as affecting the exposure and vulnerability. The absence of a national EMS policy and post-crash care system, as well as the fact that many victims lack health insurance, were noted to be the factors adversely affecting the EMS capacity.

Conclusions: There exists is a real need to substantially reduce the burden of RTIs in KMA, with ultimate goal of saving lives that are being lost needlessly and reducing the impact of injuries and trauma and the economic losses associated with it. This study offers insights into the causes of RTIs and the most appropriate ways of responding to them especially with the establishment and empowerment of predefined and structured EMS systems.

Keywords: Road traffic incidents, Exposure, Vulnerability, Emergency medical services, Kampala, Uganda

\section{Background}

In recent years, the Kampala Metropolitan Area (KMA) in particular and Uganda as a whole have been registering exponential progress in the road sector. Some roads have been fully or substantially completed; some are under construction and some are due for construction as soon as it becomes possible [1]. This crucial progress in the road sector has helped to spearhead the modest economic

\footnotetext{
* Correspondence: aardalan@tums.ac.ir

'Department of Disaster Public Health, School of Public Health, Tehran University of Medical Sciences, Tehran, Iran

${ }^{3}$ National Institute of Health Research, Tehran University of Medical Sciences, Tehran, Iran

Full list of author information is available at the end of the article
}

growth and development in Uganda. However, at the same time it has resulted, in an upsurge of road traffic incidents (RTIs) which contribute to mortality, injury, morbidity, trauma and disability [2-4]. RTIs also cost the governments, especially in the low and middle income countries (LMICs) such as Uganda, approximately 3\% of their annual Gross Domestic Product (GDP) [5].

The KMA is the fastest developing region in Uganda. It has close proximity to Kampala, the capital city of Uganda, which is the political epicenter and economic hub accounting for $80 \%$ of all of Uganda's industrial and commercial activities [6]. Most of the developed roads in good condition and Emergency Medical Service (EMS) 
facilities are concentrated in the KMA. Roads from the KMA interconnect with other regions in Uganda (East, West and North) and facilitate international traffic that flows to and from the following neighboring countries: - Burundi, the Democratic Republic of Congo, Kenya, Rwanda, South Sudan and Tanzania. This has resulted in rapid motorization happening in the KMA which has in turn increasing the risk of RTIs.

According to the police records, the highest number of all the registered RTIs in Uganda happens in the KMA. For example, a total of 22,699, 22,461, 22,272, 19,870 and 18,368 RTIs happened in Uganda in 2009, 2010, 2011, 2012 and 2013 respectively. However, 12,099 (53\%); 12,152 (54\%); 12,136 (54\%); 9935 (50\%) and 9651 (53\%) respectively were registered in KMA [7-10]. To respond to this, some concerted road safety measures enumerated later in this paper were instigated in the KMA in particular and Uganda in general. Although this is commendable the trend at which RTIs occur in Uganda and the KMA indicates that much more still has to be done. Identifying the exposure and vulnerability factors for victims of RTIs, and the factors affecting the EMS capacity to respond to RTIs needs to be done prior to the implementation of any other measures. Otherwise efforts to improve road safety will be much less effective. This preliminary work is vital if the road safety measures responding to RTIs in the KMA are to have maximum impact. The present study was designed to identifying the factors affecting the exposure $(E)$, vulnerability $(\mathrm{V})$ and emergency medical service capacity $(\mathrm{C})$ for the victims of RTIs in the KMA.

\section{Method}

This study used a Delphi technique employing a questionnaire and involving a multi-disciplinary panel of experts in three rounds. The Delphi method uses a panel of experts to investigate a complex or imprecise issue using a series of structured statements [11, 12]. At times, the views of an individual expert can be susceptible to biases so this is why the present study opted for a Delphi approach. Twenty two (22) distinguished experts were purposively contacted to participate in this Delphi study. This was after exploring their profiles and institutions of affiliation which are involved in road safety, EMS and injury prevention. It should however be noted that, no specific number of participants is recommended for Delphi surveys. Only 12 experts participated all the way up to the last Delphi round out of the 16 experts who initially participated in the first round. Their details are indicated in Table 1.

The selection criteria for the experts was as follows: (a) being recognized as an expert and being knowledgeable on the Delphi topic; (b) having accumulated a wealth of professional experience; (c) holding a key position that
Table 1 Details of the experts who completed the last Delphi round

\begin{tabular}{lll}
\hline & Details & No participants \\
\hline Gender & Male & 9 \\
& Female & 3 \\
Professional/employment & & \\
& Road safety policy and & 7 \\
& traffic accident prevention \\
& Emergency Medical Services & 3 \\
& $\begin{array}{l}\text { Researcher, academia } \\
\text { and consultancy }\end{array}$ & 6 \\
& Regulation of public & 6 \\
transport &
\end{tabular}

Level of education

$\begin{array}{ll}\text { Bachelor's Degree } & 2 \\ \text { Master's Degree } & 10\end{array}$

Years of work

$\begin{array}{ll}<3 \text { years } & 1 \\ 3-5 \text { years } & 2 \\ 6-10 \text { years } & 5 \\ 15-20 \text { years } & 2 \\ >20 \text { years } & 2\end{array}$

Other specialized training

$\begin{array}{lc}\begin{array}{l}\text { Road safety and traffic } \\ \text { related course }\end{array} & 12 \\ \begin{array}{l}\text { Accident and disaster } \\ \text { emergency care }\end{array} & 3 \\ \text { Others } & 2\end{array}$

NB: Some experts were involved in more than one profession in terms of employment and training

requires them to advise and/or oversee issues related to the Delphi topic; (d) being a researcher with recognized research and (e) being affiliated to a reputable institution. The experts selected were government bureaucrats; policy makers; traffic police commanders; academicians and researchers; consultants and emergency care specialists from public and private institutions working on road safety, injury prevention and EMS. A clear explanation about the study was made to them and if they consented (verbally), they were then requested to participate in not less than two Delphi rounds. In each round, the experts were provided with a questionnaire structured in three (3) parts, which solicited their feedback on $\mathrm{E}, \mathrm{V}$ and $\mathrm{C}$ factors as per the study topic. Before distributing the questionnaires for each of the three rounds, all the reviewers carefully reviewed them and where necessary revised them.

\section{Study area}

The KMA covers an area with an approximate $20 \mathrm{~km}^{2}$ radius (970 sq. $\mathrm{km}^{2}$ ) in the central part of Uganda. It 
stretches from Kampala, the capital city of Uganda, to other areas of Mukono, Entebbe, Nansana, Kira and Wakiso [13, 14]. Similar to Kampala, the KMA operates as part of the major business and industrial hub of Uganda - contributing to over $70 \%$ industrial production and over $60 \%$ of the country's GDP. Currently, the population in the KMA is estimated at 3.5 million and $60 \%$ of all the registered vehicles in Uganda are to be found there $[6,13-15]$.

\section{The Delphi procedures}

Round 1: Initially, 16 experts consented to receiving the open-ended questionnaire which requested their general opinions on the factors influencing the $\mathrm{E}, \mathrm{V}$ and $\mathrm{C}$ for victims of RTIs in the KMA. The experts received the questionnaire in a hard and soft copy form. Answering the questionnaire covered a period between 2 weeks and one and half months. At the beginning, the questionnaire was pretested and reviewed by all the reviewers and where necessary adjusted before being distributed to the experts both in a soft and hard copy forms.

Round 2: The experts' feedback from round one was then reviewed, modified, aggregated and converted into another well-structured questionnaire which consisted of listing a wide range factors affecting the $\mathrm{E}, \mathrm{V}$ and $\mathrm{C}$ for victims of RTIs in the KMA (Table 2). The experts were asked to rate and/or make any possible disagreements on the $\mathrm{E}, \mathrm{V}$ and $\mathrm{C}$ factors presented based on a five Likert type scale (completely agree, agree, no idea, disagree and completely disagree). These questionnaires covered a period between two weeks and one and half months. Where possible, they were also required to state the rationale of their rating and/or offer any additional opinions. The ultimate goal was to derive the ten most important factors according to experts' ranking. Only 12 experts managed to complete this round. The questionnaires were reviewed by all the reviewers and where necessary adjusted before distributing them to the experts both in a soft and hard copy forms.

Round 3: A last version questionnaire, after being validated by all the reviewers, was presented to the experts through email. It consisted of a list in a descending order of the ten highest rated factors from the previous round that were found to be influencing the $\mathrm{E}, \mathrm{V}$ and $\mathrm{C}$ for victims of RTIs in KMA. The overall aim of this round was to elicit the experts' final judgment, consensus, opinion and or/ related comments specifically relating to the ten highest rated factors. The number of experts who participated in this round remained at 12 , and the questionnaire had to be completed within a period of between 2 weeks and one and half months.

Overall, the ten highest rated factors were compared to other factors relayed in an enormity of literature like articles, reports and other publishable information on similar and/or related topics. This helped to further verify and substantiate their impact.

The ethical research requirements and approval were obtained from both the Tehran University of Medical Sciences and Office of the Vice Chancellor for Research and the Uganda National Council for Science and Technology $[16,17]$.

\section{Results}

Round one: In this survey, varying responses and opinions (Table 2) concerning the factors affecting $\mathrm{E}, \mathrm{V}$ and $\mathrm{C}$ for victims of RTIs in the KMA were given by $16 \mathrm{ex}-$ perts who initially participated in the Delphi round one between the months of August and September, 2015.

Round two: From all the factors that were given in the first round to have affected $\mathrm{E}, \mathrm{V}$ and $\mathrm{C}$ for victims of RTIs in the KMA, the ten most rated factors (Table 3) were chosen between October and November 2015.

Round three: This was the final round which took place between November and December 2015. The experts' level of agreement and consensus on the order of the ten highest rated factors influencing $\mathrm{E}, \mathrm{V}$ and $\mathrm{C}$ for victims of RTIs in KMA slightly varied from that of round 2. Five experts concurred with the list, but they suggested renaming some of the factors. Two other experts agreed with the list but suggested that to a certain degree the list order should change. They did not say how this should be done. Another 2 experts agreed with the list, but they noted that the exposure factor related to "the unregulated rise in the number of Boda-bodas" (commercial motorcycles) listed needed to be rated much higher. They justified this on the fact that the Boda-bodas are increasingly being registered as the major cause of RTIs in the KMA. The 3 remaining experts never made any comment about the list.

\section{Discussion \\ Main finding}

In this Delphi study, the factors that were identified as affecting the exposure and vulnerability of victims to RTIs in KMA were similar and multifactorial in nature. That's because they were influenced by a number of different socio-cultural, infrastructure and road safety aspects. Those factors most affecting the EMS capacity were the absence of a national EMS policy and post-crash care system as well as the fact that many victims lack health insurance. Given that multidisciplinary experts with varied knowledge; work experience; recognized researches and extramural training were convened together for this study, the factors they identified offer another opportunity to further evaluate and revise the effectiveness of existing road safety measures. The findings also augment a prior advocacy that agitated for 
Table 2 Factors noted in Delphi round one to affect the exposure, vulnerability and EMS capacity for victims of RTI in KMA

\begin{tabular}{|c|c|c|c|}
\hline & Exposure & Vulnerability & Emergency medical service capacity \\
\hline 1 & Lack of driving licenses among drivers & $\begin{array}{l}\text { Ignorance and low awareness level on road } \\
\text { safety }\end{array}$ & Crash and injury severity \\
\hline 2 & Inadequate driving training regime & Socio demographic factors & Crash type \\
\hline 3 & Indiscipline among road users & Driving/or riding incompetency & Number of affected victims \\
\hline 4 & Inadequate awareness of road safety laws & Carelessness of pedestrians and cyclists & $\begin{array}{l}\text { Time/season in order to determine the } \\
\text { deployment }\end{array}$ \\
\hline 5 & Careless road users & Lack of child accompaniment while on roads & Level of survivability \\
\hline 6 & Excessive speed & Lack of appropriate driving training & $\begin{array}{l}\text { Financial constraints and limited investment } \\
\text { in EMS }\end{array}$ \\
\hline 7 & Drinking and driving & Blindness without any guidance & $\begin{array}{l}\text { Lack of enough and well - equipped } \\
\text { ambulances }\end{array}$ \\
\hline 8 & Ineffective enforcement of traffic laws & $\begin{array}{l}\text { Inappropriate infrastructure for pedestrians and } \\
\text { non-motorized road users }\end{array}$ & Access to referral medical facilities and services \\
\hline 9 & Low risk perception among road users & $\begin{array}{l}\text { Limited interest in road safety sensitization by } \\
\text { majority road users }\end{array}$ & $\begin{array}{l}\text { Lack of basic rescue and evacuation skills } \\
\text { among lay people }\end{array}$ \\
\hline 10 & Unregulated rise of Boda-bodas & Low risk perception among road users & Occurrence of crash in certain locations \\
\hline 11 & Weather conditions & Alcohol and drug influence & $\begin{array}{l}\text { Absence of national EMS policy and post-crash } \\
\text { care system }\end{array}$ \\
\hline 12 & Poor road engineering design and planning & $\begin{array}{l}\text { Poverty leading to unaffordability of safe } \\
\text { transport means }\end{array}$ & Lack of national ambulance network \\
\hline 13 & Inefficient public transport system & $\begin{array}{l}\text { Use of handheld phones by drivers and other } \\
\text { road users while on road }\end{array}$ & $\begin{array}{l}\text { Inadequate pre-crash and post-crash data to } \\
\text { inform EMS policies }\end{array}$ \\
\hline 14 & Driving mechanically dangerous vehicles & Riding/ being transported on Boda-bodas & $\begin{array}{l}\text { Limited human capacity trained to handle } \\
\text { victims }\end{array}$ \\
\hline 15 & $\begin{array}{l}\text { Ignoring to use protective safety and } \\
\text { visibility gears }\end{array}$ & $\begin{array}{l}\text { Absence of traffic segregation facilities for } \\
\text { non-motorized road users }\end{array}$ & $\begin{array}{l}\text { No specialized EMS training courses in } \\
\text { medical schools }\end{array}$ \\
\hline 16 & Weak road safety policy in KCCA Act & $\begin{array}{l}\text { Weak enforcement of existing traffic laws } \\
\text { and regulations }\end{array}$ & Limited training and knowledge in EMS \\
\hline 17 & Poor and inadequate road furniture & Laxity in using protective gears on roads & $\begin{array}{l}\text { Lack of emergency call centers for coordination } \\
\text { of EMS activities }\end{array}$ \\
\hline 18 & $\begin{array}{l}\text { Inadequate pedestrian and cyclist } \\
\text { infrastructure }\end{array}$ & Mixed traffic streams & Unpreparedness among the first responders \\
\hline 19 & $\begin{array}{l}\text { Lack of segregated lanes AND high } \\
\text { traffic mix }\end{array}$ & $\begin{array}{l}\text { Road designs and maintenance not considering } \\
\text { vulnerable road users }\end{array}$ & Lack of health insurance by most of the victims \\
\hline 20 & Overpopulation in Kampala & $\begin{array}{l}\text { Lack of formal and informal road safety education } \\
\text { among road users }\end{array}$ & $\begin{array}{l}\text { Lack of specialized crash and trauma care } \\
\text { sections }\end{array}$ \\
\hline 21 & Increased traffic volume and flow & $\begin{array}{l}\text { Inadequate regulation of public passenger } \\
\text { transport services }\end{array}$ & $\begin{array}{l}\text { In services rotation of EMS staff due to high } \\
\text { turn-up of patients }\end{array}$ \\
\hline 22 & $\begin{array}{l}\text { Affordability and flexibility of } 2 \\
\text { wheeler riders }\end{array}$ & Inadequate public transport system & $\begin{array}{l}\text { Inadequate advocacy for establishing } \\
\text { formalized EMS systems }\end{array}$ \\
\hline 23 & Poor traffic lighting & Poor street lighting & $\begin{array}{l}\text { Traffic jams preventing timely emergency } \\
\text { response to victims }\end{array}$ \\
\hline 24 & $\begin{array}{l}\text { Political patronage in road } \\
\text { safety enforcement }\end{array}$ & & \\
\hline
\end{tabular}

establishing a well-structured EMS system to cater for the ever increasing emergency demands being placed on health and medical units beyond even the KMA $[2,4,18,19]$.

\section{Influence of sociocultural factors to RTIs}

In regard to the findings in this Delphi study; the factors related to driver indiscipline; driving under the influence of alcohol and drugs; failure to use adequate safety equipment (seat belts, helmets, visibility reflectors and child restraints) and excessive speeding were often induced by different road users' cultures, behaviors and perceptions. Other factors were demographically attributed to age, peer influence and the economic status. Some of these factors were identified in other studies to contribute to the underlying causes of RTIs in LMICs 
Table 3 Ten most rated factors affecting exposure, vulnerability, and EMS capacity for RTI victims in KMA

\begin{tabular}{|c|c|c|c|}
\hline & Exposure & Vulnerability & Emergency medical service capacity \\
\hline 1 & Indiscipline among different road users & Alcohol and substance abuse & Limited staff and well - equipped ambulances \\
\hline 2 & Inadequate driving training regime & $\begin{array}{l}\text { Lack of appropriate infrastructure for } \\
\text { pedestrians and non-motorized road users }\end{array}$ & $\begin{array}{l}\text { Lack of a National EMS policy and post-crash } \\
\text { care system }\end{array}$ \\
\hline 3 & Drinking and driving & $\begin{array}{l}\text { Absence of traffic segregation facilities for } \\
\text { non-motorized road users }\end{array}$ & Occurrence of crash in certain locations \\
\hline 4 & Lack of segregated lanes and high traffic mix & Unaccompanied children on road & Lack of national ambulance network \\
\hline 5 & Inadequate pedestrian and cyclist infrastructure & Mixed traffic streams & $\begin{array}{l}\text { Lack of public awareness about emergency } \\
\text { call centers }\end{array}$ \\
\hline 6 & $\begin{array}{l}\text { Ignoring to use protective safety and } \\
\text { visibility gears }\end{array}$ & $\begin{array}{l}\text { Demographic aspects (age, sex, peer influence, } \\
\text { economic status, and domicile) }\end{array}$ & $\begin{array}{l}\text { Lack of health insurance by most victims } \\
\text { to pay for EMS }\end{array}$ \\
\hline 7 & Poor road engineering design and planning & $\begin{array}{l}\text { Laxity in using protective gears like reflectors, } \\
\text { helmets and seat belts }\end{array}$ & $\begin{array}{l}\text { Lack of specialized crash and trauma care } \\
\text { sections }\end{array}$ \\
\hline 8 & Unregulated rise of Boda-bodas & $\begin{array}{l}\text { Road designs and maintenance not considering } \\
\text { vulnerable road users }\end{array}$ & $\begin{array}{l}\text { Poor and uncoordinated pre and } \\
\text { post-crash care }\end{array}$ \\
\hline 9 & Excessive speed & $\begin{array}{l}\text { Inadequate regulation of public passenger } \\
\text { transport services }\end{array}$ & Limited trained health care specialist \\
\hline 10 & $\begin{array}{l}\text { Lack of driving permits/or licenses } \\
\text { among drivers }\end{array}$ & Lack of appropriate driving training & Unpreparedness among first responders \\
\hline
\end{tabular}

including a systematic review study on the trend of RTIs in Kampala and Uganda at large [20-24]. Similar findings in other studies also showed how introverted and extroverted cultural attitudes, behaviors and perceptions were stronger predictors of involvement in RTIs both in high income countries and LMICs, which included Uganda $[25,26]$. However, the contribution of these factors to RTIs were exacerbated by the other factors like the rapid motorization and unprecedented population growth in the KMA.

\section{Road infrastructure}

The aforementioned road sector in Uganda has been progressing especially in the KMA with the benefits of the region having the most roads in fairly good condition. Approximately $1300 \mathrm{~km}^{2}$ (43\%) of paved roads exist in the KMA out of $3000 \mathrm{~km}^{2}$ of total paved roads in Uganda [6, 13, 14]. Despite this advantage the highest number of RTIs in Uganda were recorded in the KMA as mentioned above. Aside other challenges, the conditions of many roads in the KMA are still poor and others lack vital traffic safety and pedestrian infrastructure. For instance, Kampala city has approximately $1200 \mathrm{~km}^{2}$ of road network but only $20 \%$ of it is in fair condition [6].

Again, the majority of roads in the KMA lack necessary traffic signs and pedestrian facilities such as speed humps, warning signs, demarcated bus-stops, zebra crossing, footbridges and crosswalks as well as pedestrian reflectors. Yet these traffic signs and facilities are required for regulating the traffic flow and alerting road users about potential hazards along roads which ultimately help to reduce RTIs [27]. This validates some of the $\mathrm{E}$ and $\mathrm{V}$ factors that were underscored to affect victims of RTIs in the KMA by the experts because their causes mostly emanate from road design and construction challenges. They include: lack of segregated lanes; inadequate road furniture; poorly planned-engineering; mixed traffic streams; poorly designed roads and the absence of traffic segregation facilities for non-motorized road users. These are similar with other findings in most of the LIMCs [20, 28, 29], which are attributed to a lack of a systematic approach in preventing RTIs [30, 31].

\section{Road safety}

It is pleasing to report that over the recent years, multisectoral road safety measures were instigated to respond to the heavy burden of RTIs. These included the deployment of more traffic and highway police along roads to police for road violations; efforts to increase public awareness and sensitization; greater coordination efforts and proactive road safety audits [7-10]. They have also been augmented by the enacting of regulations covering driving permits (2005); weighing bridges (2009) and driving schools and driver instructors (2010). The Ministry of Works and Transport in Uganda has been taking a lead role in their implementation in collaboration with other stakeholders [32, 33].

The above road safety measures are in-tandem with the national, regional and international road safety frameworks based on the Uganda National Road Safety Action Plan and United Nations General Assembly Action for the Road Safety Action 2010-2020 and are to be commended [33, 34]. However, much more is still needed to achieve effective implementation and enforcement of road safety in the KMA considering some 
factors which were noted in the Delphi surveys. These include: an inadequate driver training regime; ignoring use of protective equipment; drinking and driving; excessive speed; lack of driving permits; and the inadequate regulation of public passenger transport services. Most of these factors have been also highlighted by the World Health Organization, and they are also in line with the findings in another study $[29,35]$.

\section{Distribution of victims}

Based on RTI records all the road users (pedestrians, passengers, riders of motorized 2 or 3 wheelers, motor and pedal cyclists and drivers of different vehicles) in the KMA are susceptible to being involved in RTIs [7-10]. Some road users are vulnerable to RTIs largely because of their own reckless actions or inactions. Pedestrians and passengers, however, are commonly much more vulnerable to becoming innocent victims of RTIs compared to other road users [7-10,36-38]. The riders and passengers of the 2 wheeler Boda-bodas (commercial motorcycles) have also increasingly become vulnerable to RTIs.

Of recent, the numbers of Boda-bodas have been exponentially rising to the point that it now predominates the public transport system of the KMA and Uganda $[3,24,36,38,39]$. They are mainly manned by the youths who seek to make-ends-meet. Boda-bodas have been dubbed a 'silent killer' and they not only cause serious injuries and fatalities but also a significant economic burden $[3,19,36-40]$. Some of the reasons attributed to this include failure to wear and use protective safety and visibility gear and equipment (helmet and reflectors); failure of riders to comply with the traffic signals; riding at exorbitant speeds where it is unnecessary and dangerous. Researcher further indicates that the severity of injuries of the victims involved in Boda-boda crashes in Kampala city is greatly increased particularly by the failure of both motorcyclists and their passengers to wear protective gear [3, 37-39]. It is therefore necessary to rank the unregulated rise of the Boda-bodas higher among the factors exposing victims to RTIs in KMA as some experts suggested.

\section{Emergency medical services}

The absence of a national EMS policy and post-crash care system are compounded by other factors known to affect the EMS capacity. This problem has been identified before in various studies. One of the studies was concerned about the lack of a well-functioning prehospital emergency and trauma care system which can be widely accessible [19]. Two studies which assessed the pre-hospital care for victims of RTIs observed that it's often left to police with the help of community leaders, taxi drivers and lay people who are ill-equipped and untrained to deliver suitable emergency medical care $[4,18]$. Other studies noted that due to the absence of a pre-hospital emergency care system in Kampala, many patients arrive too late and those with serious injuries may die before they receive the emergency care they need. Others die immediately upon arrival to accident and emergency units due to poor emergency care they received before $[2,41]$.

Ideally, a definitive and well-planned emergency care system needs to be urgently put in place. That should greatly help to significantly reduce deaths, injuries, morbidity and disability adjusted life years (DALYS) caused by RTIs [42]. That would facilitate quick life-saving care and improve treatment which reduces and prevents life threatening injuries due to the potential effects of RTIs. The establishment of a well-planned and coordinated EMS system based on patient needs over time has been previously called for in different forums. As a result of this advocacy the Uganda National Ambulance Services (UNAS) [43], was established to coordinate ambulancerelated activities in Uganda. This was a positive step forward, however, much is still to be done considering some of the factors identified through the Delphi process that affect the EMS capacity.

\section{Health insurance for victims of RTIs}

At times, depending on the injury severity, the emergency care for RTI victims can be complex requiring more resources and quick responses compared to those needed by other patients. It can thus, require and precipitate hurried and costly resource deployment [44]. However, this remains a challenge in many LMICs and Uganda is no exception, where the structured EMS systems are not yet in place. In a study on unintentional childhood injury in Kampala, it was found that only 3\% of victims were treated on insurance [36]. Similarly, another study noted that less than $5 \%$ of patients in Kampala were brought to health facilities by the few existing ambulances, most of which were privately run and prohibitively expensive [4]. Notwithstanding other factors, the findings of both studies could be attributed to the lack of a mandatory national health insurance policy in Uganda. Currently, fairly good EMSs in Kampala are privately offered, but at a premium. Free EMS is available in the government funded public health facilities. The poor and low-income earners involved in RTIs run the risk of not receiving quality EMS if they can't easily access it. Therefore, since RTIs are unpredictable events, there's a great need for Uganda to come-up with a mandatory national health insurance policy because it was identified in this study to be one of the main factors affecting the EMS capacity. A national health insurance system, if adopted, should also consider subsidizing the EMS to cater for all patients' needs, especially for poor and low income earners. 


\section{Study strength and limitations}

A noteworthy strength of this study is that it managed to convene multidisciplinary experts to deliberate on a common public health challenge affecting the KMA in particular and Uganda at large. Fortunately, $50 \%$ of the panelists were members of Uganda National Council of Road Safety. Therefore the factors that were listed to affect the $\mathrm{E}, \mathrm{V}$ and $\mathrm{C}$ are dependable and oriented by the experts' across multiple professions; educational levels; work experiences; research; and extramural training beyond the arena of road safety and EMS.

On the other hand, the experts' opinions should not be conclusive, and some caution is advisable while interpreting them based on two reasons. First, the definition of an expert is subjective and the criteria, which was used to select the experts, was to some degree influenced by references and networks. This might have accrued some degree of bias. Second, the Delphi method only explores areas of concern raised by the panel of experts, and so other important areas other than the main topic of discussion might have been overlooked.

\section{Conclusion}

This study explored the factors affecting the E, V and C for victims of RTIs in KMA through the Delphi technique which involved a number of multidisciplinary experts on road safety, injury prevention and EMS. The socio-cultural, infrastructure and road safety aspects were identified as factors influencing the victims' exposure and vulnerability to RTIs. The absence of a national EMS policy and post-crash care system, as well as the fact that many victims lack health insurance, were noted to be the factors adversely affecting the EMS capacity. Although a multiplicity of road safety measures are in place to reduce the burden of RTIs, there exists a real need to substantially reduce the burden of RTIs in the KMA, with ultimate goal of preventing needless deaths; reducing the impact of injuries and trauma and the economic losses associated with it. An urgent need is similarly required to establish and empower of predefined and structured EMS systems. This study offers some useful insights on the factors that were identified to affect the $\mathrm{E}, \mathrm{V}$ and $\mathrm{C}$ for victims of RTIs in the KMA drawn from a panel of experts, and should guide any measures taken to respond to the burden of RTIs in the KMA and elsewhere in Uganda.

\section{Abbreviations}

C: Emergency medical capacities; E: Exposure; EMS: Emergency medical services; KMA: Kampala Metropolitan Area; LMICs: Low and middle-income countries; RTIs: Road traffic incidents; TUMS: Tehran University of Medical Sciences; UNCST: Uganda National Council of Science and Technology; $\vee$ : Vulnerability

\section{Acknowledgment}

All the efforts of distinguished experts in Uganda who devoted their time to participate in this Delphi study are greatly appreciated. Special thanks to Paul Sinclair for proof reading and editing this paper.

\section{Funding}

This is part of the PhD thesis under the support of the Tehran University of Medical Sciences - International Campus, Tehran Iran.

\section{Availability of data and materials}

The datasets supporting the conclusions of this article are not available since it was based on the personal views of experts who were guaranteed that their privacy would be strictly maintained.

\section{Authors' contributions}

JKB and AA conceived the study and developed its design. JKB, AA, AN and DKZ designed and edited the Delphi questionnaire. JBK and SK established relevant Delphi panelists. JKB conducted the Delphi panels and wrote the paper. AA, AM, DKZ and KS critically reviewed and analyzed the data. All authors read and approved the final article.

\section{Competing interests}

The authors declare that they have no competing interests.

\section{Ethics approval and consent to participate}

Acquired from Tehran University of Medical Sciences and Uganda National Council of Science and Technology.

Individual person's data

Not applicable.

\section{Author details}

${ }^{1}$ Department of Disaster Public Health, School of Public Health, Tehran University of Medical Sciences, Tehran, Iran. ${ }^{2}$ Tehran University of Medical Sciences - International Campus, Tehran, Iran. ${ }^{3}$ National Institute of Health Research, Tehran University of Medical Sciences, Tehran, Iran. ${ }^{4}$ Harvard Humanitarian Initiative, Harvard University, Cambridge, USA. ${ }^{5}$ Safety Promotion and Injury Prevention Research Center, Shahid Beheshti University of Medical Sciences, Tehran, Iran. ${ }^{6}$ Department of Health in Disaster and Emergency, School of Health, Safety and Engineering, Shahid Beheshti University of Medical Sciences, Tehran, Iran. ${ }^{7}$ Department of Clinical Science and Education, Karolinska Institute, Stockholm, Sweden. ${ }^{8}$ Department of Emergency Medicine, Imam Khomeini Hospital, Tehran University of Medical Sciences, Tehran, Iran. ${ }^{9}$ Directorate of Road Traffic and Road Safety, Uganda Police Force, Kampala, Uganda.

Received: 19 April 2016 Accepted: 6 December 2016

Published online: 07 January 2017

\section{References}

1. Kiwanuka M. Budget Speech Financial Year 2013/14: The Journey Continues: Towards Socio-Economic Transformation for Uganda. Kampala; 2013. [cited 2016 March ].

2. Kobusingye OC, Guwatudde D, Owor G, Lett RR. Citywide trauma experience in Kampala, Uganda: a call for intervention. Inj Prev J. 2002;8(2):133-6.

3. Kigera JWM, Naddumba EK. Patterns of injuries after road traffic crashes involving Bodabodas. Ann Afr Surg. 2010;5:12-5.

4. Sudha J, R Mabweijano JR, Lipnick M.S, Caldwell N, Miyamoto J, Wangoda J, Mijumbi C, Hsia R, Dicker R, Ozgediz D. Current Patterns of Prehospital Trauma Care in Kampala, Uganda and the Feasibility of a Lay-FirstResponder Training Program. World J Surg. 2009.

5. World Health Organization. Global status report on road safety 2015. Geneva: WHO; 2015.

6. Kampala Capital City Authority. Strategic plan 2014/15-2018/19: laying the Foundation for Kampala City Transformation. Kamapala: KCCA; 2015.

7. Uganda Police Force. Annual crime and traffic/Road safety report 2009. Kampala: UPF; 2009.

8. Uganda Police Force. Annual crime and traffic/Road safety report 2010. Kampala: UPF; 2010.

9. Uganda Police Force. Annual crime and traffic/Road safety report 2011. Kampala: UPF; 2011. 
10. Uganda Police Force. Annual crime and traffic/Road safety reports 2013. Kampala: UPF; 2013

11. Goodman CM. The Delphi technique: a critique. J Adv Nurs. 1987;12:729-34.

12. Gordon TJ, editor. The Delphi method. Futures research methodology, vol. 3.0. 2001.

13. Japan International Cooperation Agency. The study on greater Kampala Road Network and transport improvement in the Republic of Uganda: final report. Kampala: JICA; 2010.

14. Ministry of Works and Transport. National Transport Master Plan (NTMP) for the Greater Kampala Metropolitan Area 2008-2023. Kampala: MoWT; 2008.

15. Uganda Bureau of Statistics. State of Uganda Population. Kampala: UBOS; 2014

16. Tehran University of Medical Sciences. Official letter - Project Number: 9213648001-145814. Tehran: Vice Chancellor for Research; 2015.

17. Uganda National Council of Science and Technology. Research registration number SS-3797. Kampala: Executive Secretary; 2015.

18. Sudha J, Mabweijano JR, Lipnick MS, Caldwell N, Miyamoto J, Wangoda J, Mijumbi C, Hsia R, Dicker R, Ozgediz D. First things first: effectiveness and scalability of a basic prehospital trauma care program for lay first responders in Kampala, Uganda. PLoS One. 2009:4(9):1-7.

19. Otieno T, Phillips J, Mbonye B, Beyeza T, Naddumba E. Prehospital and first health facility management of patients with severe musculoskeletal injuries in Uganda. East Cent J Surg. 2011;16(3):45-50.

20. Haghparast-Bidgoli $H$, Hasselberg M, Khankeh HR, Khorasani ZD, Eva J. Barriers and facilitators to provide effective pre-hospital trauma care for road traffic injury victims in Iran: a grounded theory approach. BMC Emerg Med. 2010;10:20

21. Khorasani ZD, Khankeh H, Mohammadi R, Laflamme L, Bikmoradi A, Haglund BJ. Post-crash management of road traffic injury victims in Iran. Stakeholders' views on current barriers and potential facilitators. BMC Emerg Med. 2009;9:8.

22. Bigdeli M, Khorasani ZD, Mohammadi R. Pre-hospital care time intervals among victims of road traffic injuries in Iran. A cross-sectional study. BMC Public Health. 2010;10:406

23. Khorasani-Zavareh D, Mohammadi R, Khankeh H, Laflamme L, Bikmoradi A, Haglund BJ. The requirements and challenges in preventing of road traffic injury in Iran. A qualitative study. BMC Public Health. 2009;9:486.

24. Balikuddembe KJ, Ardalan A, Khorasani ZD, Nejati A, Kasiima MS. Road traffic incidents in Uganda: A systematic review study of five years trend. J Inj Violence Res. 2016;9(1)

25. Trond NSJ, Torbjorn R. Cultural and socio-demographic predictors of car accident involvement in Norway, Ghana, Tanzania and Uganda. Saf Sci. 2012;50:1862-72

26. Trond NSJ, Torbjorn R. Culture related to road traffic safety: a comparison of eight countries using two conceptualizations of culture. Accid Anal Prev. 2014;62:319-28

27. Bunn F, Collier T, Frost C, Ker K, Roberts I, Wentz R. Traffic calming for the prevention of road traffic injuries: systematic review and meta-analysis. Inj Prev J. 2003:9:200-4

28. Khorasani ZD, Bohm K, Khankeh H, Mohammad TT, Mohammadi R, Bigdeli M, Castren M. Why should being visible on the road? A challenge to prevent road traffic injuries among pedestrians in Iran. J Inj Violence Res. 2015;7(2):93-4.

29. Peden $\mathrm{M}$, et al. World report on road traffic injury prevention. Geneva: World Health Organization; 2004.

30. Khorasani ZD, Mohammadi R, Laflamme L, Naghavi M, Zarei A, Haglund BJ. Traffic injury deaths in West Azarbaijan province of Iran: a cross-sectional interview-based study on victims' characteristics and pre-hospital care. Int J Inj Contr Saf Promot. 2009;16(3):119-26.

31. Khorasani-Zavareh D. System versus traditional approach in road traffic injury prevention: a call for action. J Inj Violence Res. 2011;3(2):61.

32. Nasasiira J. Response on behalf of Uganda Government. In: Call for a decade of action for road safety: launch of the second report of the commission for global road safety: 5th May 2009. Rome - Italy. 2009.

33. Government of Uganda. Uganda National Road Safety Action Plan 2015-2017. Kampala: MoWT; 2015.

34. United Nations. United Nations Decade of Road Safety Action: 2011-2020. Kampala, New York; 2010.

35. Khorasani ZD, Shoar S, Saadat S. Antilock braking system effectiveness in prevention of road traffic crashes in Iran. BMC Public Health. 2013;13:439.

36. Khorasani ZD, Mohammadi R, Laflamme L, Naghavi M, Zarei A, Haglund BJ. Estimating road traffic mortality more accurately: use of the capturerecapture method in the West Azarbaijan province of Iran. Int J Inj Contr Saf Promot. 2008;15(1):9-17.
37. Mutto M, Lawoko S, Nansamba C, Ovuga E, Leif S. Unintentional childhood injury patterns, odds, and outcomes in Kampala City: an analysis of surveillance data from the National Pediatric Emergency Unit. J Inj Violence Res. 2011;3(1):13-8.

38. Kamulegeya LH, Kizito M, Nassali R, Bagayana S, Elobu AE. The scourge of head injury among commercial motorcycle riders in Kampala; a preventable clinical and public health menace. Africa Health Sci. 2015;15(3):1016-22.

39. Galukande M, Jombwe J, Fualal J, Gakwaya A. Boda-boda injuries a health problem and a burden of disease in Uganda: a tertiary hospital survey. East Cent J Surg. 2009;14(2):33.

40. Naddumba EK. A cross-sectional retrospective study of Boda Boda injuries at Mulago in Kampala - Uganda. East Cent Afr J Surg. 2004;9(1):44-7.

41. Nakiyimba G. Boda-Boda: Uganda's silent killer. Kampala; 2012. Retrieval Source http://en.rfi.fr/africa/20120325-boda-boda-ride-silent-killer-uganda. Accessed Mar 2016.

42. Kigera JWM, Naddumba EK. Injury to presentation delays among musculoskeletal trauma patients in Uganda. East Afr Orthop J. 2011;5:36-9.

43. Kobusingye OC, Hyder AA, Bishai D, Manjul J, Eduardo RH, Mock C. Chapter 68: Emergency medical services in low and middle income countries: recommendations for action. Bull World Health Organ. 2005;83(8):1261-79.

44. Ministry of Health. Uganda National Ambulance Service. Kampala; 2014 [cited 2016].

\section{Submit your next manuscript to BioMed Central and we will help you at every step:}

- We accept pre-submission inquiries

- Our selector tool helps you to find the most relevant journal

- We provide round the clock customer support

- Convenient online submission

- Thorough peer review

- Inclusion in PubMed and all major indexing services

- Maximum visibility for your research

Submit your manuscript at www.biomedcentral.com/submit

Biomed Central 